\title{
EDITORIAL
}

\author{
Francesco dell'Isola • Victor A. Eremeyev • Peter Schiavone
}

\section{A special issue in honor of Prof. David Steigmann}

Received: 19 June 2015 / Accepted: 19 June 2015 / Published online: 8 July 2015

(c) Springer-Verlag Berlin Heidelberg 2015

This special issue of Continuum Mechanics and Thermodynamics celebrates the award of the International Levi Civita Prize (2013) and the Engineering Science Medal conferred by the Society of Engineering Science (2013) to David Steigmann of the University of California, Berkeley. Professor Steigmann is a distinguished scholar having made fundamental contributions to diverse areas of continuum mechanics and to the mechanics of structures ranging from finite elasticity and plasticity theory to the mechanics of thin films/substrate systems, electromagnetic phenomena in solid mechanics, variational methods, elastic stability, and the biomechanics of cells. In the same spirit, this special issue showcases papers in several areas of mechanics all of which have been influenced in some way by the inspiring contributions of Professor Steigmann. In particular, the issue includes papers from nonlinear elasticity, the mechanics of thin structures, and the analysis of surface effects in solids, an area in which Professor Steigmann is regarded as one of the founding contributors. The authors contributing to this issue are friends, colleagues, former students, and postdoctoral fellows of Professor Steigmann, all of which have benefitted from his tireless efforts in mentorship, collegiality and his willingness to support and encourage beginning researchers. We have all been inspired by Professor Steigmann, and we carry the memories of our interactions with him wherever we go. We wish Professor Steigmann the best of health, energy, and happiness in the coming years as we look to many more years of his contributions to this wonderful field of mechanics.

Professor Steigmann accomplishments have been recognized widely in the world community of scientist working in mechanics. Beyond the SES Medal, he also was awarded with the Levi-Civita Prize (for more details, see at http://memocs.univaq.it/?page_id=4144). We reproduce here the Laudatio which was read by Francesco dell' Isola while offering him this prize.

F. dell'Isola

Dipartimento di Ingegneria Strutturale e Geotecnica, Sapienza Università di Roma, Via Eudossiana,

18, 00198 Rome, Italy

E-mail: francesco.dellisola@uniroma1.it; fdellisola@gmail.com

V. A. Eremeyev ( $\varangle)$

Faculty of Mechanical Engineering, Institute of Mechanics, Otto von Guericke-University,

Universitätplatz 2, 39106 Magdeburg, Germany

E-mail: eremeyev.victor@gmail.com

V. A. Eremeyev

South Scientific Center of RASci and South Federal University, Milchakova St. 8a, 344090 Rostov on Don, Russia

P. Schiavone

Department of Mechanical Engineering, Faculty of Engineering, University of Alberta, Edmonton, AB T6G 2G8, Canada

E-mail: p.schiavone@ualberta.ca 


\section{INTERNATIONAL LEVI CIVITA PRIZE \\ LAUDATIO \\ Professor DAVID STEIGMANN}

In Europe a tradition was established since the foundation of first universities: every chair had a prestige based on the list of predecessors who had occupied it. In some university (e.g. Padua University) at the entrance of every Department one can read the list of Professors who had occupied the chairs belonging to that Department since the foundation of the University.

Of course this is a practice which can be disputed, as the principle of authority is somehow to be regarded with suspicion when science and scientific knowledge is involved. However to belong to an ancient and highly regarded institution, although it is neither a sufficient nor a necessary condition for assessing individual quality, it still remains a hint to be considered for such an assessment.

Professor David Steigmann is an academic successor of Professor Naghdi on one of the chairs of Mechanics of the University of California at Berkeley. Professor Naghdi knew of David Steigmann during the first part of his career and carefully checked the quality if the papers he authored: this is—for sure - an objective check of David Steigmann's high standing in the world mechanics community. The relationship between Prof. Naghdi and Prof. Steigmann has many features in common with the interaction between scientists of the Renaissance and immediate later periods: their contacts and ties were established exclusively via mailed letters.

Of course some Europeans belonging to universities which were founded earlier than seven centuries ago could track in their academic genealogy many and important predecessors, and — of course — the relatively young institutions from USA cannot compete on this ground.

The successors of Tullio Levi-Civita on the chairs of Rational Mechanics at the Universita di Roma La Sapienza and the other members of the selection committee for the International Levi-Civita Prize-in principle-refrain from any consideration concerning the prestige of position occupied by and the relevance of the scientific network connected to any candidate for the prize. Even if it is more difficult, more time consuming and demanding, the Levi-Civita Prize scientific committee, as a method, decided to acquire direct knowledge about the competence, the scientific achievements and standing of every candidate to the Prize.

Even if David Steigmann is not a serial writer and has bibliometric indicators which are not artificially distorted by an aggressive self-advertisement policy, it can be stated that his research is deep, sound and authoritative, his papers will have a permanent impact on mechanical sciences and his contribution is original, creative and absolutely nonstandard. This statement needs to be substantiated by some scientific arguments to which I will dedicate some time in this discourse.

I needed - for pursuing my own research work-to study personally some of his papers of which I will briefly discuss here their content. Those phenomena occurring at phase interfaces are challenging theoretical mechanicians since the époque of Laplace. Indeed this is a controversial subject since its very first treatment and indeed in the necrology dedicated by Gabrio Piola (a not—enough-known Italian Mathematical Physicist) to Vincenzo Brunacci (his Maestro) one can already read.

The Journal of Physical Chemistry of Pavia was illustrated in many of its pages by Brunacci's erudite pen; I will content myself to indicate here three Memoirs where he examines the doctrine of capillary attraction of Mr. Laplace, comparing it with that of Pessutti and where with his usual frankness, which is originated by his being persuaded of how well-founded was his case, he proves with his firm reasonings, whatever it is said by the French geometers, some propositions which are of great praise for the mentioned Italian geometer. Here we will refrain from polemical disputes and will simply start by praising the following two rather impressive papers:

Steigmann, D.J., Li, D. Energy-minimizing states of capillary systems with bulk, surface, and line phases (1995) IMA Journal of Applied Mathematics (Institute of Mathematics and Its Applications), 55(1), pp. 1-17,

Steigmann, D.J. Fluid films with curvature elasticity (1999) Archive for Rational Mechanics and Analysis, 150(2), pp. 127-152.

In the first one some very interesting and physically meaningful necessary conditions for energy-minimizing states of fluid systems consisting of bulk, surface, and line phases are discussed in the spirit of Laplace and Pessutti. Some generalizations of the Laplace and Young equations of equilibrium are obtained together withvery intuitive but very intricate to obtain - a demonstration that the line tension associated with a three-phase contact curve must be nonnegative.

In the second one it is discussed a purely mechanical Cosserat theory incorporating local constraints on the director field to model the phenomenology of surfactant fluid-film microstructures interspersed in bulk fluids: these films are assumed to be a material surfaces consisting of a fixed set of mass particles. After having described those balance and constitutive laws which are needed to formulate a well-posed problem the relevant 
Legendre-Hadamard inequality for energy-minimizing equilibria is obtained and used to motivate a simple proposal for the description of bilayer response.

I have personally studied similar problems very carefully and I must remark that the sources-especially in delicate aspects of differential geometry and the continuum mechanics of bidimensional bodies-used by David and myself are the same, as we use exactly the same notations: this means that I could have a personal positive bias in judging it. I have to say indeed that I found really lucid and original the whole treatment and in particular I believe that the energy minimizing conditions are novel and very important.

Another very ancient subject concerns the study of one-dimensional continua by means of variational methods: indeed already Euler and the Italian Gabrio Piola gave relevant contributions to it.

Again thanks to Professor Antonio Di Carlo, with whom I had the honor to collaborate as an assistant professor at the beginning of my career, I had the opportunity to work in very similar subjects and therefore I appreciated very much the results presented by David in the following two papers

Steigmann, D.J., Faulkner, M.G. Variational theory for spatial rods (1993) Journal of Elasticity, 33(1), pp. $1-26$,

Steigmann D The Variational structure of a nonlinear theory for spatial lattices Meccanica 31,4 (1995).

In these papers it is developed a theory for the equilibrium of spatial lattice and are derived and analyzed some interesting necessary conditions for the existence of their stable configurations when subjected to conservative dead-loads.

Finally in the last years I worked a lot in non-linear elasticity. A masterpiece in this discipline is the following paper, whose reading is very useful to those who want to understand.

Steigmann, D.J. Frame-invariant polyconvex strain-energy functions for some anisotropic solids (2003) Mathematics and Mechanics of Solids, 8(5), pp. 497-506

The most striking feature of the personality of David Steigmann is his capacity to act in a rational way in all moments of his life. I am honored by his friendship and I regret that circumstances did not allow me to meet him before.

I must tell that knowing him well one can state that he personifies the Latin phrase

Amicus Plato, sed magis amica veritas Which can be translated into "Plato is my friend, but truth is a better friend (literally: Plato is friend, but truth is more friend (to me than he is))."

As in the case of William of Baskerville (Guglielmo da Baskerville) the fictional friar from the novel "Il nome della rosa" (The Name of the Rose) by Umberto Eco, Professor Steigmann's bigger sin is well known: when he is right he wants that this has to be recognized.

I did not dare to contradict him and therefore-as he is particular proud of some of his papers-I decided to read them carefully. I must admit that it was an exciting experience.

I am talking about the two papers:

Steigmann, D.J. Puncturing a thin elastic sheet International Journal of Non-Linear Mechanics, 40(2-3), pp. 255-270 (2005)

Nadler, B., Steigmann, D.J. Modeling the indentation, penetration and cavitation of elastic membranes Journal of the Mechanics and Physics of Solids, 54(10), pp. 2005-2029 (2006)

In the first one a membrane theory is used to analyze the puncturing (that is the formation of a traction free hole in its center) of a thin solid circular isotropic elastic sheet by a rigid axisymmetric indenter. In the second one a model for the penetration of an elastic membrane by a rigid cylindrical indenter is presented. In both cases very elegant energetic arguments are presented and very difficult problems are solved with an astonishing (apparent) simplicity. In particular conditions are determined for the onset of cavitation phenomenon in which the membrane is detached from the indenter and a central traction-free hole is maintained by boundary data alone.

I must agree with David. He is right: these are most likely his best papers. 